\title{
Evaluation of the subject geological area suitability for oil recovery by High-Pressure Air Injection method
}

\author{
Aysylu Askarova ${ }^{1}$, Alexander Cheremisin ${ }^{1}$, John Belgrave ${ }^{2}$, Aleksei Solovyev ${ }^{3}$, Raj Mehta ${ }^{4}$, and Alexey Cheremisin ${ }^{1}$ \\ ${ }^{1}$ Integrated Center for Hydrocarbon Recovery, Skolkovo Institute of Science and Technology, Moscow, 121205, Russia \\ ${ }^{2}$ Belgrave Oil and Gas Corporation, Calgary, T2P 3E8, Canada \\ ${ }^{3}$ Zarubezhneft LLC, Moscow, 101990, Russia \\ ${ }^{4}$ Department of Chemical and Petroleum Engineering, University of Calgary, Calgary, T2N 1N4, Canada
}

Correspondence: Aysylu Askarova (aysylu.askarova@skolkovotech.ru)

Received: 5 June 2020 - Revised: 4 August 2020 - Accepted: 12 August 2020 - Published: 3 September 2020

\begin{abstract}
The considerable decline of conventional oil and gas reserves and respectively their production introduces new challenges to the energy industry. It resulted in the involvement of hard-to-recover reserves using advanced enhanced oil recovery (EOR) techniques. Thermal methods of EOR are recognized as most technically and commercially developed methods for the highly viscous crude oil. High-Pressure Air Injection (HPAI) is one of the thermal production methods that reduce oil viscosity and increases recovery. HPAI has already been effectively applied for different types of reservoirs development and proven to be economically feasible. The application performance of the HPAI technology strongly depends on the quality of experimental and numerical modeling conducted on the target object basis. Before the field tests, physicochemical and thermodynamic characteristics of the process were studied. Further consequent numerical modeling of laboratory-scale oxidation experiments and field-scale simulation was conducted to estimate HPAI method feasibility based on the results of oxidation studies. A medium pressure combustion tube (MPCT) oxidation experiment was carried out to provide stoichiometry of the reactions and field design parameters. A 3D numerical model of the MPCT experiment was constructed taking into account the multilayer design, thermal properties, heating regimes, and reaction model. The "history" matched parameters such as fluid production masses and volumes, temperature profiles along the tubes at different times and produced gas composition demonstrated good correspondence with experimental results. The results obtained during the experiment and modeling of MPCT (fluid properties, relative phase permeability, kinetic model, technological parameters) were used in
\end{abstract}

field-scale modeling using various thermal EOR scenarios. Air breakthrough into production wells was observed, thus a $2 \%$ oxygen concentration limit where implied. The overall performance of four different scenarios was compared within 30 years timeframe. The development system was also examined to achieve the maximum economic indicators with the identifications of risks and main uncertainties.

\section{Introduction}

High-Pressure Air Injection (HPAI) is one of the most effective and economically profitable enhanced oil recovery (EOR) techniques in case of light oils at deep, thin, highpressure fields with low permeability (Gutiérrez et al., 2008; Montes et al., 2018; Moore et al., 1996; Sutherland et al., 2007). Compressed air is injected into a reservoir during the HPAI process to mobilize the oil and increase the sweep efficiency. The process is governed by the combustion kinetics initiated by the spontaneous ignition of injected air (Yoshioka et al., 2017). The compressed air reacts with some fraction of oil in place, acting as fuel at high-temperatures and high-pressures. In case, when the oil is not reactive enough for spontaneous ignition, it might be by use of a downhole heater or other artificial ignition techniques (Moore et al., 1996; Sutherland et al., 2007).

The growing interest in HPAI is dictated by the increase in oil demand, as well as the economic success of HPAI projects within the last decades. There is a list of successful projects at various types of reservoirs, and companies started to investigate the applicability of this process both on their onshore 
and offshore fields (Gutiérrez et al., 2008; Ismail et al., 2016; Moore et al., 2007; Sutherland et al., 2007). The combination of favorable aspects such as high recovery factor, less energy, and water consumption, and availability of the injectant together makes HPAI an emerging technology. However, the risks coupled with the presence of oxygen in the injected air and its further breakthrough to production wells are significant issues that must be examined before its implementation at any reservoir (Batenburg et al., 2010). The first example of an extended field test of HPAI in a deep, thin light-oil reservoir in Nebraska demonstrated good prospects, but due to low oil prices ( $\sim$ USD 3 per bbl), this project was proved to be uneconomical. Meanwhile, the second application with similar conditions (West Heidelberg project) and at oil prices $\sim$ USD 4 per bbl was both economically and technically successful. At the early stage, the increase in oil production was due to pressure maintenance, but thermal effects led to more than half of the cumulative oil production (Gutiérrez et al., 2008).

Few key factors are affecting the overall performance of HPAI project design such as air compressors, screening of the prospects, laboratory screening of candidate reservoirs, numerical modeling, etc. At the project operation stage it is crucial to monitor the process, oil displacement at elevated temperatures, and revise the operating strategies. Nevertheless, the main two requirements are the ability of the oil to sustain the combustion reactions, and a sufficient rate of air to maintain these oxidation reactions in the bond scission or combustion modes. These requirements can be examined only through appropriate laboratory studies at the reservoir conditions and their further numerical simulation (Moore et al., 2007). The increase in the recovery coefficient can be achieved only using good quality experimental data, numerical studies, and history matching on the samples of the target field to avoid any uncertainties. Despite the wide availability of the published literature, the behavior of oxidation kinetics, the nature of the fuel for combustion kinetics and importance of thermal effects are still subject of numerous studies (Barzin et al., 2010; Gutiérrez et al., 2008; Khakimova et al., 2020; Montes et al., 2018).

In the presented research HPAI method feasibility at the target mid-deep, light-oil reservoir was examined based on the results of oxidation studies on a laboratory scale and further upscaled to the field. The studied field belongs to the North Kinelsky oil and gas region, with an average depth of $1339 \mathrm{~m}$ and crude oil with a gravity of $33.2^{\circ}$ API. Medium pressure combustion tube (MPCT) test was carried out using rock and oil samples of the target field (Mallory et al., 2018; Gutiérrez et al., 2012; Rodriguez et al., 2012). A 3D numerical model of the MPCT experiment was constructed with an appropriate agreement with the design of experimental equipment to reduce constructional uncertainties such as multilayer design, thermal properties, and heating regimes. More details about the field, technical characteristics of the equipment, initial parameters of the system, the whole pro- cedure, and its further simulation are presented in the article Khakimova et al. (2020). Adapted kinetic scheme (Belgrave et al., 1997) was "history matched" against MPCT test results. The results obtained during the experiment and modeling of MPCT (fluid properties, relative phase permeability, kinetic model, technological parameters) were used further in field-scale modeling. The performance of the four different thermal EOR scenarios was assessed. The development system was also examined to achieve the maximum economic indicators with the identifications of risks and main uncertainties.

\section{Physical and numerical simulation on a laboratory scale}

Before the field tests, physicochemical and thermodynamic characteristics of the process were studied to avoid any risks and uncertainties. According to the methodology, the development of a thermodynamic model starts form HighPressure Differential Scanning Calorimetry (HPDSC) and High-Pressure Ramped Temperature Oxidation (HPRTO) laboratory tests. They were carried out to obtain the temperature dependence of the thermal effect and to estimate the oxidation characteristics as a function of temperature. Then a laboratory experiment is conducted to simulate the process of HPAI itself on an MPCT. It allows validating the kinetic model and technological parameters. This research focuses on the results of the MPCT oxidation experiment, its further consequent simulation to provide stoichiometry of the reactions, and field design parameters.

\subsection{Experimental part}

The experiment was carried out on the MPCT laboratory setup. The schematic representation of the MPCT installation is presented in Fig. 1. Before air injection, Helium was injected to pressurize the system, and the first zone was heated up. The air injection started with a rate of $15.34 \mathrm{stl} \mathrm{h}^{-1}$ and the start of temperature rise with a speed of $40^{\circ} \mathrm{Ch}^{-1}$. The end of air injection occurred after $20.44 \mathrm{~h}$ that followed with a helium injection at a rate of $15.34 \mathrm{stl} \mathrm{h}^{-1}$ and further the pressure was dropped after $31.23 \mathrm{~h}$. The maximum temperatures achieved as a result of combustion reactions at each zone are presented in Fig. 2b. The maximum temperature achieved in zone 1 was $526^{\circ} \mathrm{C}$. Temperature profiles demonstrate that the combustion front did not reach the 11th and 12th zones as the air was switched to Helium after zone 10 peaked. The combustion front velocity with a temperature of $350{ }^{\circ} \mathrm{C}$ through zones $3-10$ was $18.1 \mathrm{~cm} \mathrm{~h}^{-1}$. Figure $2 \mathrm{a}$ shows the mole concentration of $\mathrm{O}_{2}, \mathrm{~N}_{2}, \mathrm{He}, \mathrm{CO}$, and $\mathrm{CO}_{2}$. According to the composition change in Fig. $2 \mathrm{a}$ in the interval from 2.5 to $8 \mathrm{~h}$, the stabilization of the component composition of gases leaving the MPCT is observed, which corresponds to the steady-state combustion mode. 


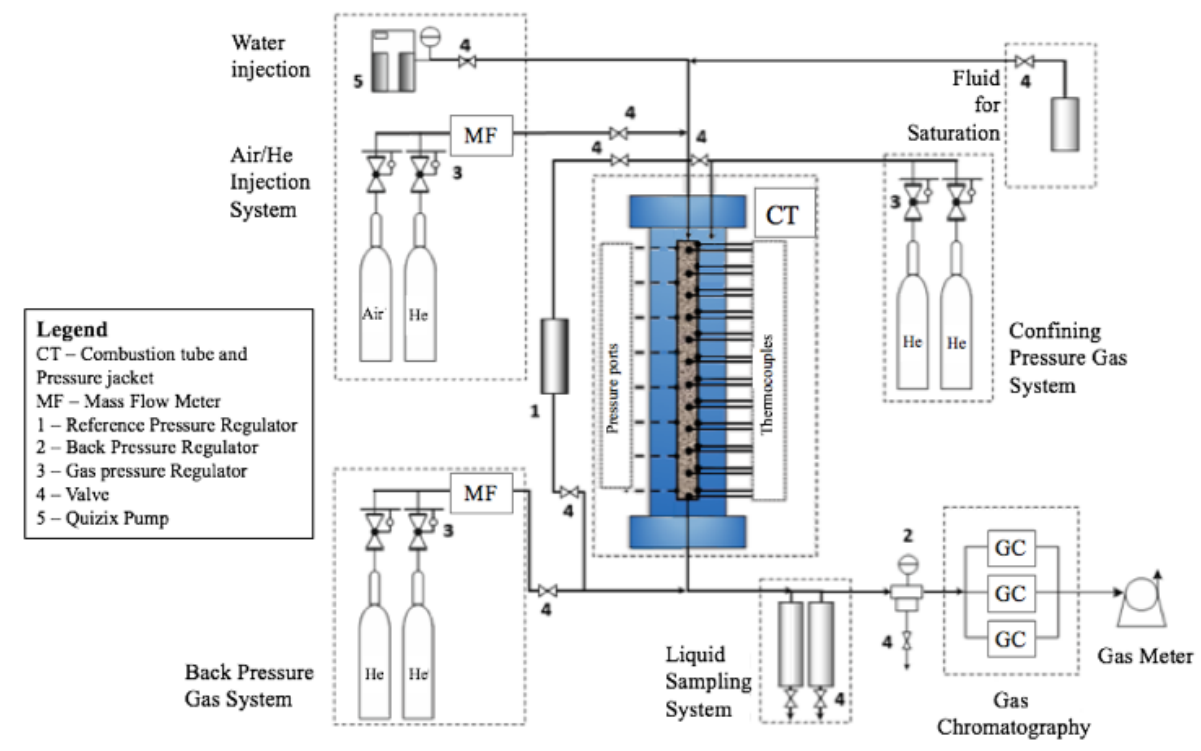

Figure 1. Schematic diagram of the MPCT installation (Khakimova et al., 2020).
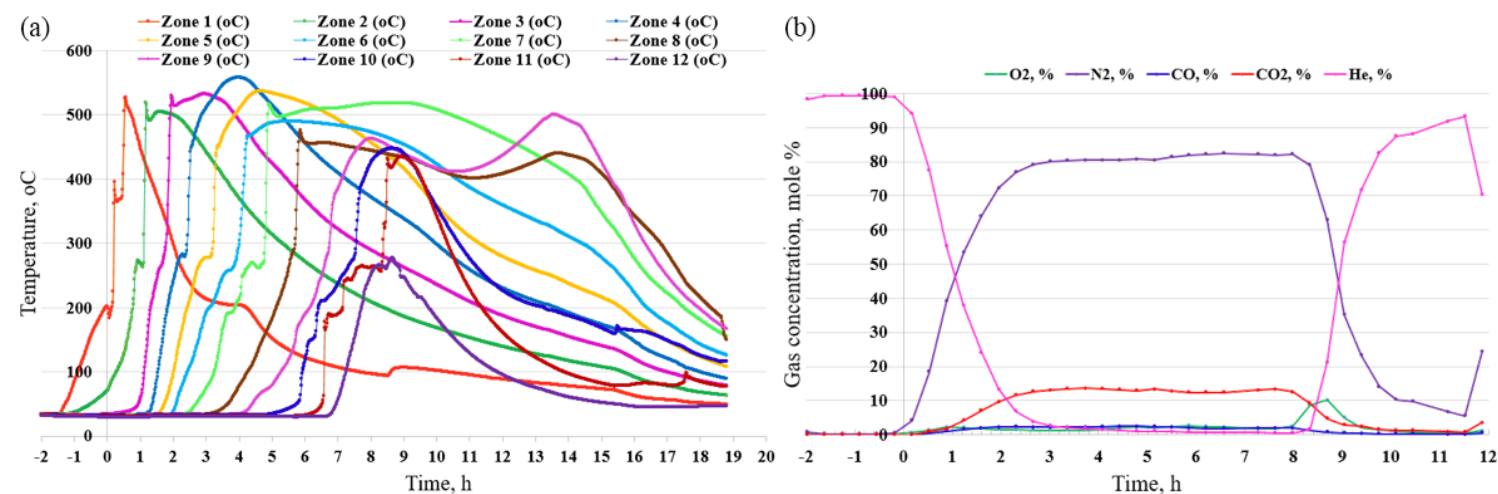

Figure 2. Temperature profiles on the centreline (a); Combustion gas mole concentrations (b).

\subsection{Numerical modeling}

A 3D radial model of the MPCT experiment (see Fig. 3) was created in CMG commercial software to "history match" the model of chemical reactions, sufficient air injection rate, and relative permeability curves. Details about the importance of the full multilayer design, appropriate simulation of heater regimes, and "history matching" of all stages preceding the air injection process are described by Khakimova et al. (2020). The combustion tube is $1.83 \mathrm{~m}$ with 12 heating zones presented in temperature profiles (see Fig. 2a). The centerline and wall thermocouples, as well as heating elements mounted in these zones, were reproduced in the numerical model. The tube is displayed in 11, 1, and 45 grid blocks in the radial, azimuthal, and vertical direction, respectively (see Fig. 3). The three central cells represent the rock sample with $40 \%$ porosity and permeability of 15.6 darcy. This rock layer is then followed by a steel tube wall, insu- lation, steel wall, annular space, and pressure casing. The values of porosity and permeability of each layer and their sizes are given in the article Khakimova et al. (2020). The initial oil, water, and gas saturations were calculated based on the experimental data of initial masses of oil and water contained in the core and accounted for $0.739,0.111$, and 0.150 respectively. The amount of Maltenes mole fraction was 0.995 . The numerical model accounted for the gradual increase of the pressure in the system, initiation of the combustion, maintenance of the necessary temperatures according to the work of heaters during the experiment, switching to Helium, and the gradual release of pressure in the system. The reproduction of the angle of inclination of the temperature profile during cooling of the zone was achieved by introducing heat loss coefficients to surroundings. Pseudocomponents used in the model are Water, Methane, Maltenes, Asphaltenes, $\mathrm{CO}_{2}, \mathrm{H}_{2} \mathrm{~S}, \mathrm{~N}_{2}, \mathrm{O}_{2}$ and Coke. The reaction scheme includes thermal cracking, low-temperature oxida- 
(a)

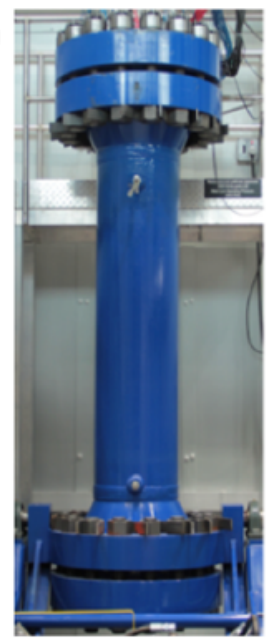

(b)

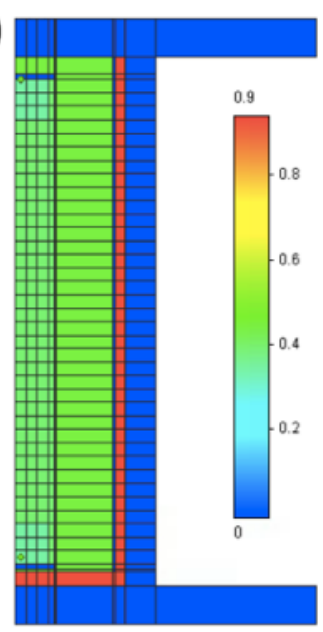

(c)

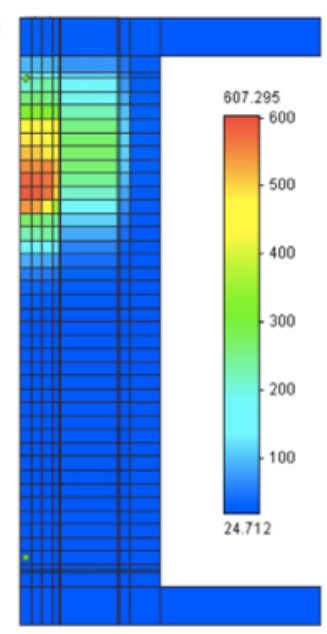

(d)

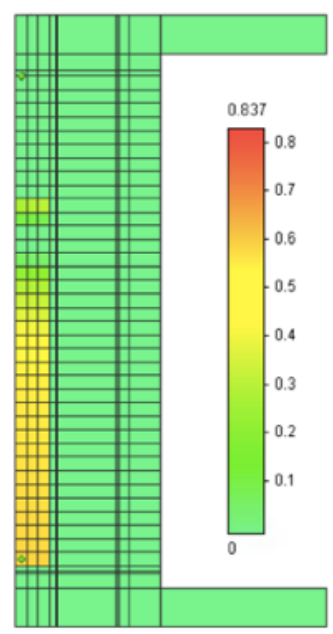

Figure 3. MPCT Installation (a) and the numerical model of the MPCT in CMG STARS: initial porosity (b), temperature distribution over time (c), oil saturation distribution over time (d).

tion, and high-temperature oxidation reactions as described in Khakimova et al. (2020).

The numerical modeling of the MPCT experiment was performed in the thermal hydrodynamic simulator. The "history matching" was carried out by varying the kinetic parameter and the operation regimes of the heaters. Results revealed a significant impact of relative permeability curves on the combustion tube simulation and they further were used in field-scale modeling. Figure 4 represents the temperature profiles for particular zones and demonstrates considerably good reproducibility. Figure $5 \mathrm{a}$ and $\mathrm{b}$ demonstrates the cumulative $\mathrm{O}_{2}$ and $\mathrm{CO}_{2}$ production during the experiment and simulation. Figure $5 \mathrm{c}$ shows the dynamics of water production and a comparison of the accumulated water production for the experiment and numerical simulation. Figure $5 \mathrm{~d}$ shows the comparison of cumulative oil production for the experiment and numerical simulation. There is a mismatch in the cumulative production of $\mathrm{O}_{2}$ and $\mathrm{CO}_{2}$, indicating the requirement of expanded investigation of phase transition behavior of studied oil. Nevertheless, the obtained numerical model demonstrates excellent reproduction of general features of the MPCT experiment (temperature peaks, front velocity, cumulative oil, and water). Thus, the validated numerical model can be further tested during upscaling.

\section{Field-scale modeling}

Results from numerical modeling of laboratory-scale oxidation experiments were further applied for field-scale simulation to estimate HPAI method feasibility. The geological model of the target field was compiled based on the results of the reinterpretation of 2D, 3D seismic surveys, and deep hole drilling data. The field is a single-layer with seven oil deposits discovered in the formation of the Tournaisian stage of the Lower Carboniferous. The average depth of the field is $1340 \mathrm{~m}$, with a thickness of the oil-saturated part in the range of $1.2-13.8 \mathrm{~m}$. The gravity of the crude oil is $33.2^{\circ}$ API. An average oil saturation is $75 \%$. Other main characteristics of the individual subsectors are presented in Table 1 . The construction of the HPAI model was conducted in CMG commercial software (CMG, 2016). Figure 6 presents the distribution of oil saturation of the model with four subsections of interest. Generally, objective functions are selected that can allow the estimation of the degree of discrepancy between the calculations by large-block and small-cell models. Based on the stability analysis of the large-block model, further thermophysical, chemical, and filtration parameters can be selected. Based on the results of the "history matching" of the MPCT experiment, the pre-exponential Arrhenius parameters and relative permeability curves were obtained. These kinetic reactions and pseudo-compositional model (see Sect. 2.2) were transferred to the sector model. The pre-exponential factors for three oxidation reactions and order with respect to oxygen partial pressure for Asphaltenes low-temperature oxidation were reduced as a part of the upscaling process. It improved the numerical performance caused by the degree of reservoir heterogeneity and relative permeability curves.

Four scenarios of field development were examined to evaluate the efficiency of air injection on individual subsections. The scenarios considered: (1) Primary recovery method (without injecting water or air); (2) Air injection; (3) Waterflooding; (4) Simultaneous injection of air and water (wet combustion).

The performance of each subsection is presented in Fig. 7. Subsection 1 demonstrates promising predictions for scenario 2 and scenario 4, with $9 \%$ and $10 \%$ additional cumulative oil production, respectively, in comparison with scenario 3. It was achieved by improved perforations in the pay area. 

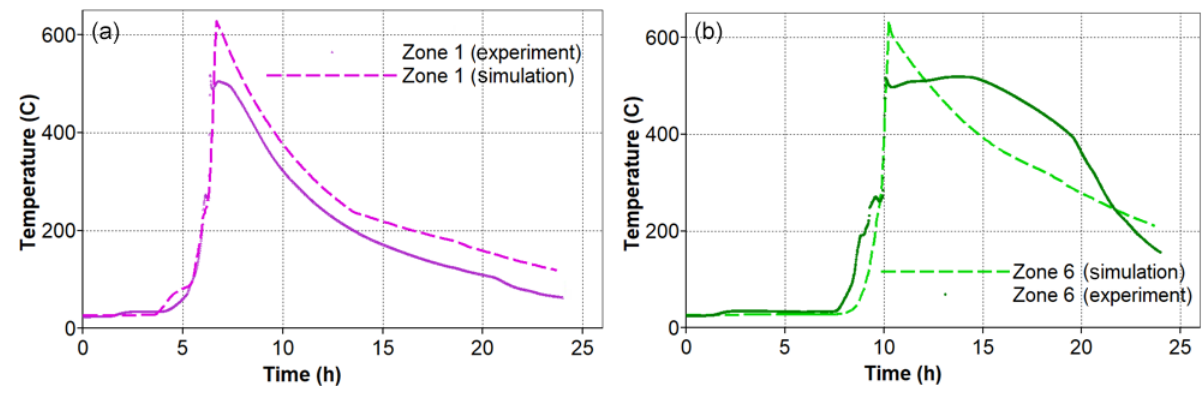

Figure 4. Temperature profiles: Zone 1 (a); Zone 6 (b).

(a)

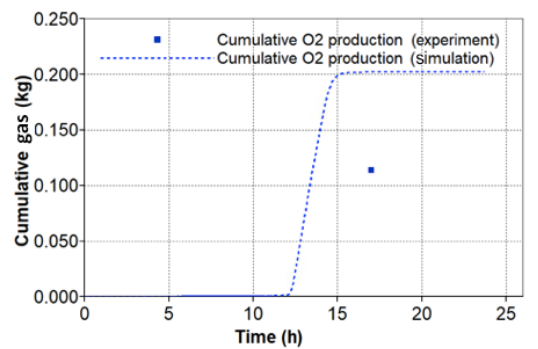

(c)

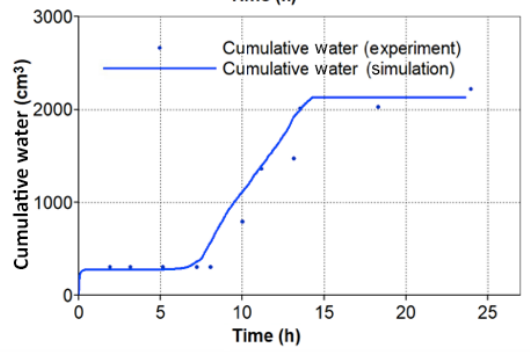

(b)

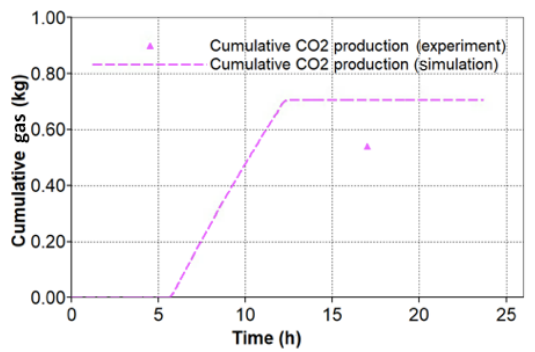

(d)

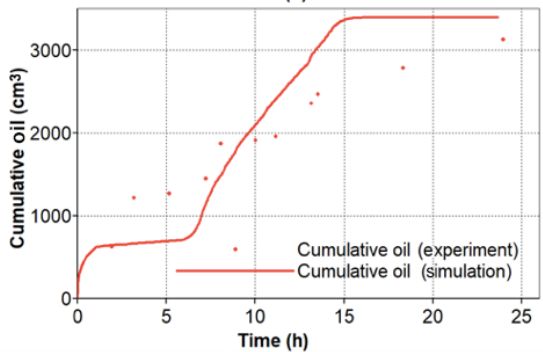

Figure 5. Cumulative $\mathrm{O}_{2}$ (a), $\mathrm{CO}_{2}$ (b), water (c) and oil (d) production production for experiment and simulation.

Separation of oil-saturated layers was ensured, and air injectivity was improved due to low rock permeability and relative permeability to gas. Meanwhile, the high-temperatures in air-injection well cross-sections indicate combustion existence in subsections 2 and 3 (see Fig. 7c and d). However, the amount of oxygen is insufficient to maintain the required pressure at a distance of more than $50 \mathrm{~m}$ from the well in subsections 2, 3 and 4 due to insufficient injectivity of the injector. Combustion stops and air breakthrough into the production wells. In the calculations for scenarios 2 and 4 , restrictions were placed on the production wells (shutting down the wells when the concentration of $\mathrm{O}_{2}$ was reached $2 \%$ ). In the long run, the water injection and primary production demonstrate a better efficiency and more profitable with the given development system of subsections $2,3,4$. It should be noted, the efficiency of water injection is overestimated, since in practice, it does not show such effectiveness. The limited availability of water and the need for water treatment are other drawbacks of scenario 3.

Further subsections 2 and 3 were considered as a subject of optimization. They were analyzed in detail to find the optimal injection scenario and to achieve maximum oil production.
The rearrangement of subsection 3 (see Fig. 8) only demonstrated the effectiveness of air-injection based methods in comparison with water injection. The development system of this uplift was changed as follows: one well (yellow) was converted from injection mode to production, another well (blue) from production to injection mode, and an additional well was drilled. (see Fig. 8a). In this case, an option with water + air injection is more effective than the option with water injection until November 2021 (see Fig. 8b). The results showed that by optimizing the development system, it is possible to increase the efficiency of field development. An economic factor should play a key role in the identification of the best solution. The effectiveness of the scenarios 1,3 in these models is due to the high ratio of gas and oil mobility provided by relative permeability tables in the oil-gas system. 
Table 1. Model characteristics.

\begin{tabular}{lrrrr}
\hline Model characteristics & Subsection 1 & Subsection 2 & Subsection 3 & Subsection 4 \\
\hline Number of active grids & 20486 & 40434 & 14447 & 13327 \\
Average porosity, \% & 11.2 & 12 & 12.1 & 12.1 \\
Average permeability, mD & 59 & 84 & 94 & 82 \\
Pore volume, $\mathrm{m}^{3}$ & 8342974 & 16288440 & 6446607 & 5581886 \\
Initial geological oil reserves, $\mathrm{m}^{3}$ & 781532 & 2405516 & 1365192 & 1087928 \\
\hline
\end{tabular}
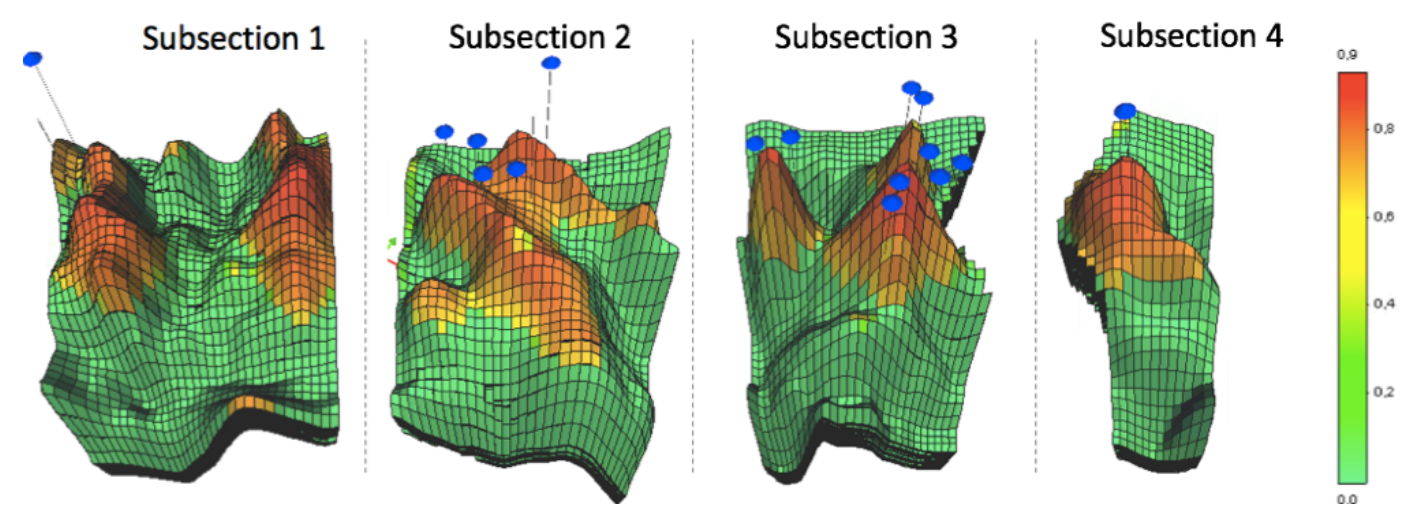

Figure 6. Oil saturation distribution of different subsections.

\section{Conclusions}

This research focuses on the estimation of the HPAI recovery technique feasibility for the target field. Consequent laboratory-scale HPRTO and MPCT experiments, and their further 3D numerical modeling were performed. A kinetic model of reactions occurring during combustion was validated against experimental results. Adapted fluid model, relative permeability, kinetic model, and operational parameters obtained during the numerical simulation were used for the field upscaling.

Four different field-wide development scenarios were considered to maximize oil production. The methods were tested on existing wells during the 30 years period and compared to assess the performance of air injection: primary recovery, air injection, water injection, and simultaneous injection of water and air. The simulation was performed for four individual subsections to evaluate the efficiency of each method. High temperatures in air-injection well cross-sections indicate combustion existence. In subsection one due to improved perforation strategy scenario two adds $4 \%$, and scenario 4 , in its turn, adds $10 \%$ to cumulative oil production in comparison with scenario three. Injection of air into the reservoir does not lead to an increase in oil recovery in the long run for subsections 2, 3 and 4 due to rapid breakthroughs of air into producing wells within 3-4 years (oxygen concentration limit is $2 \%$ ). A lack of sufficient air injectivity in parts of the reservoir resulted in an inability to sustain combustion at these locations. The relatively low porosity requires a high amount of fuel to heat the rock matrix. Low air-injectivity at subsections 2, 3 and 4 the geological features (permeability, porosity, pay zone thickness) and current well pattern led to insufficient oil displacement. For the subsection 2, the optimization with converting injector to the producer, production well into injection mode, as well as drilling an additional well, can lead to higher oil production $(+16 \%)$ until 2021 (after which production wells were shut off due to air breakthrough).

Currently, the main uncertainties that significantly affect the results are relative permeability curves in the oil-gas system, possible air breakthroughs into production wells, injectants (water and air) availability, and their costs.

Code availability. The simulations for this work are done in CMG STARS and are available upon request.

Author contributions. AA performed MPCT numerical simulation and field numerical simulation, preparations of the results, and wrote this article. JB performed initial field numerical simulation and provided expert recommendations for field operational strategy optimization. AlexaC led the simulation and analysis of the results, AlexeC set the research goals, supervised the research project, and analyzed the results. RM helped with the research methodology, experimental design, screening methods and conceptualization of the article. All authors reviewed the manuscript.

Competing interests. The authors declare that they have no conflict of interest. 


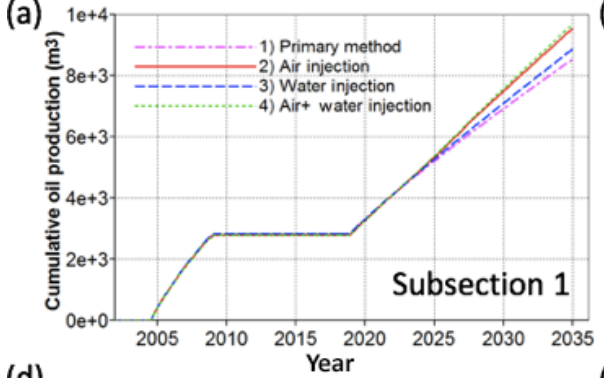

(d)

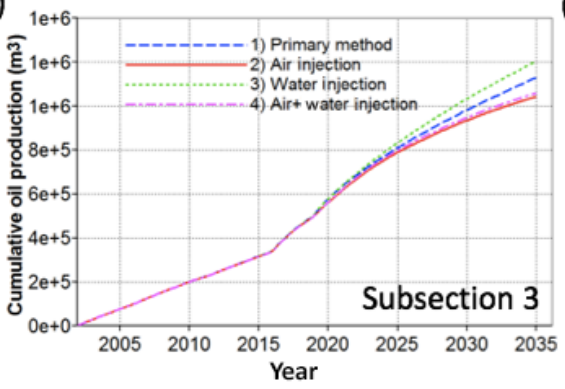

(b)

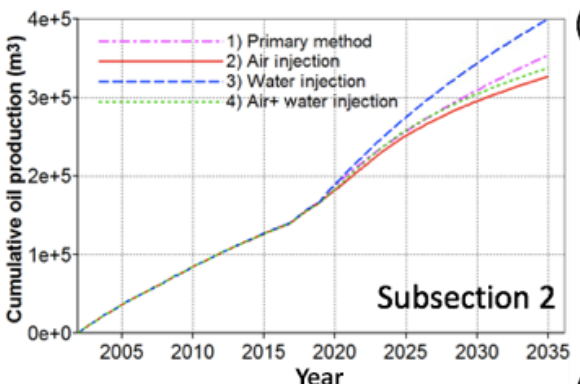

(e)

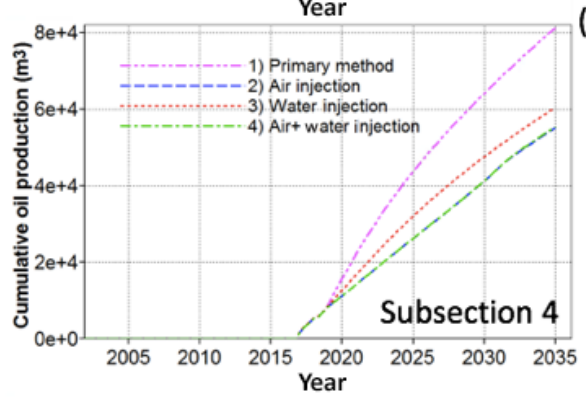

(c)

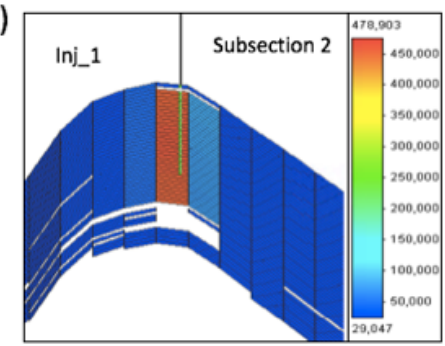

(f)

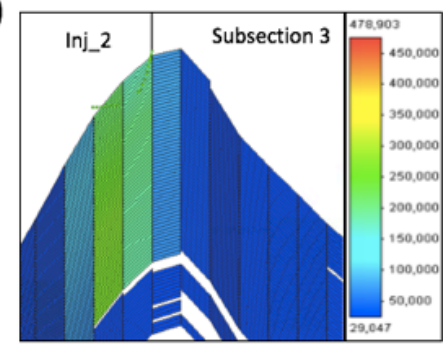

Figure 7. Cumulative oil production for 4 subsections $(\mathbf{a}, \mathbf{b}, \mathbf{d}, \mathbf{e})$ and temperature profiles for scenario 2 in subsections 2 (c); subsection 3 (f).
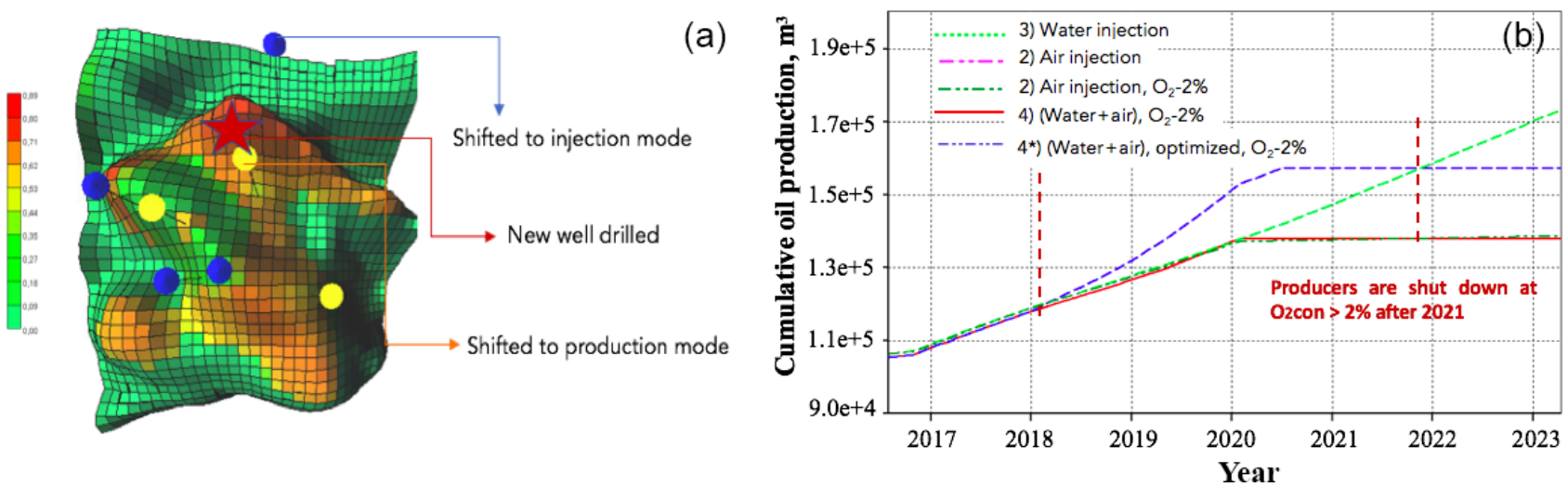

Figure 8. Optimization scenario (a) and cumulative oil production (b) for subsection three before air breakthrough.

Special issue statement. This article is part of the special issue "European Geosciences Union General Assembly 2020, EGU Division Energy, Resources \& Environment (ERE)"'. It is a result of the EGU General Assembly 2020, 4-8 May 2020.

Acknowledgements. The authors would like to acknowledge the researchers of Skoltech Integrated Center for Hydrocarbon Recovery who helped to conduct the experiments.

Review statement. This paper was edited by Viktor Bruckman and reviewed by Olga Hachay and one anonymous referee.

\section{References}

Barzin, Y., Moore, R. G., Mehta, S. A., Mallory, D. G., Ursenbach, M. G., and Tabasinejad, F.: Role of vapor phase in oxidation/combustion kinetics of high-pressure air injection (HPAI), in: Proceedings of SPE Annu. Tech. Conf. Exhib. 7, Florence, Italy, 19-22 September 2010, 5581-5598, https://doi.org/10.2118/135641-ms, 2010.

Batenburg, V. D. W., Zwart, D. A. H., and Doush, M.: Water alternating high pressure air injection, in: Proceedings of SPE Symp. Improv. Oil Recover, Tulsa, Oklahoma, USA, 2, 979-990, 2010.

Belgrave, J. D. M., Moore R. G., and Ursenbach, M. G.: Comprehensive Kinetic Models for the Aquathermolysis of Heavy Oils, J. Can. Pet. Technol., 36, 38-44, 1997.

CMG: STARS User Guide, Calgary, Alberta, Computer Modeling Group (CMG), 2016.

Gutiérrez, D., Taylor, A. R., Kumar, V. K., Ursenbach, M. G., Moore, R. G., and Mehta, S. A.: Recovery factors in high- 
pressure air injection project revisited, SPE Reserv. Eval. Eng., 11, 1097-1106, https://doi.org/10.2118/108429-PA, 2008.

Gutiérrez, D., Moore, R. G., Ursenbach, M. G., and Mehta, S. A.: The ABCs of in-situ-combustion simulations: From laboratory experiments to field scale, J. Can. Petrol. Technol., 51, 256-267, https://doi.org/10.2118/148754-PA, 2012.

Ismail, N. B., Klock, K. A., and Hascakir, B.: In-Situ Combustion Experience in Heavy Oil Carbonate, SPE Canada Heavy Oil Technical Conference, Calgary, Alberta, Canada, 7-9 June 2016, SPE-180724-MS, https://doi.org/10.2118/180724-ms, 2016.

Khakimova, L., Askarova, A., Popov, E., Moore, R. G., Solovyev, A., Simakov, Y., Afanasiev, I., Belgrave, J., and Cheremisin, A.: High-pressure air injection laboratoryscale numerical models of oxidation experiments for Kirsanovskoye oil field, J. Pet. Sci. Eng., 188, 106796, https://doi.org/10.1016/J.PETROL.2019.106796, 2020.

Mallory, D. G., Moore, R. G., and Mehta, S. A.: Ramped Temperature Oxidation Testing and In Situ Combustion Projects, Energ. Fuel., 32, 8040-8056, https://doi.org/10.1021/acs.energyfuels.8b00760, 2018.

Montes, A. R., Moore, R. G., Mehta, S. A., Ursenbach, M. G., and Gutierrez, D.: Is high-pressure air injection (HPAI) simply a fluegas flood?, Canadian International Petroleum Conference 2008, Calgary, Alberta, Canada, 17-19 June 2008, 2018.

Moore, R. G., Laureshen, C. J., Ursenbach, M. G., Mehta, S. A., and Belgrave, J. D. M.: Combustion/Oxidation Behavior of Athabasca Oil Sands Bitumen, in: Proceedings of Improved Oil Recovery Symposium, SPE/DOE Improved Oil Recovery Symposium, Tulsa, Oklahoma, USA, 21-24 April 1996, 1-8, https://doi.org/10.2118/35392-MS, 1996.
Moore, R. G., Mehta, S. A., and Ursenbach, M. G.: A Guide to High Pressure Air Injection (HPAI) Based Oil Recovery, SPE/DOE Improved Oil Recovery Symposium, Tulsa, Oklahoma, USA, 13-17 April 2002, https://doi.org/10.2118/75207-ms, 2007.

Rodriguez, E., Ordonez, A., Comas, J. C., Trujillo Portillo, M. L., and Belgrave, J. D. M.: A Framework for Consolidating Air Injection Experimental Data, in: SPE Latin America and Caribbean Petroleum Engineering Conference, Society of Petroleum Engineers, Mexico City, Mexico, 9, https://doi.org/10.2118/152048MS, 2012.

Sutherland, R. B., Hammawa, H., Moore, R. G., Mehta, S. A., and Ursenbach, M. G.: Mitigating explosion risks in high pressure air injection compressors, J. Can. Pet. Technol., 46, 55-60, https://doi.org/10.2118/07-08-06, 2007.

Yoshioka, Y., Sasaki, K., Takatsu K., and Sugai, Y.: Screening of Major Chemical Reactions in In-Situ Combustion Process for Bitumen Production from Oil Sands Reservoirs, Int. J. Pet. Petrochemical Eng., 3, 82-92, https://doi.org/10.20431/24547980.0304008, 2017. 